\title{
Marginalisation as a Possible Health Issue: an Exercise in Practice-Based Ethical Education
}

\author{
Trine Myhrvold \\ Høgskolen i Oslo og Akershus, trine.myhrvold@hioa.no
}

With the point of departure in the ongoing discussion of the professional and moral responsibility for those who are not equally included in the established health services, the question of how to include individuals and groups facing marginalisation is one of the major challenges within the ethics of care. This makes marginalisation a core concept in our time, which is challenged by, among other things, differentness with respect to ethnicity and social status as well as breach with norms and laws. The representation of individuals and groups facing marginalisation is not merely an intellectual question, however, but an epistemological one with political, practical and ethical implications. This article discusses a pilot project exploring what we can do within nursing education to sensitise students to professional and moral responsibility for individuals and groups facing marginalisation. A dialogical approach to knowledge, including cooperation with voluntary organisations and low-threshold facilities with a long tradition of trying to prevent people from 'falling through the net', was chosen to highlight the professional challenges and the ethical dilemmas that arise in the interface between closeness and distance, caring and marginalisation. Evaluation of data indicated that such an approach to knowledge seems to benefit the students' learning.

Keywords: marginalisation, professional and moral responsibility, educational reorientation, participation

\section{Introduction}

In the area of marginalisation, there is most likely a complex interplay between each and every individual's vulnerability and discrepancies between human rights, national laws and financing systems. Language barriers and cultural constraints may also affect an individual's ability to apply for assistance as well as the health professionals' ability to assess a person's need for health care. Including individuals and groups at risk of marginalisation is a major challenge within as well as outside of the established health services.

Including individuals and groups at risk of marginalisation is however, addressed by the International Council of Nurses' Code of Ethics as well as by the National Curriculum Regulations for Nursing Programmes in Norway. The International Council of Nurses addresses educators' and researchers' responsibility 'to include references to human rights, equity, justice and solidarity as the basis for access to care' and 'to sensitise students to the importance of social action in current concerns' in the Code of Ethics for Nurses 
(ICN 2006). The Code further states that 'it is a guide for action based on social values and needs. It will have meaning only as a living document if applied to the realities of nursing and health care in a changing society' (p. 38). The nurses' professional and ethical responsibility for socio-political health decisions locally, nationally and globally and to meet the special needs of vulnerable groups actively also are main points in the Ethical Guidelines for Nurses (the Norwegian Nurses' Organization (NNO) 2011), based on the Code.

According to the National Curriculum Regulations for Nursing Programmes in Norway $(2004,2008)$, nursing education should be in accordance with the Ethical Guidelines for Nurses based on the Code, the United Nations Declaration of Human Rights and other international declarations, as well as professional standards. It is also important that our curriculum defines target groups as healthy and marginalised population groups, people affected by illness and injuries or people in the terminal phase of life. However, there is no further description of how marginalisation should be understood, which circumstances may lead to marginalisation or who the marginalised population groups might be in our society.

What we can do to develop nursing education in accordance with these claims is therefore an important question. In this article, I discuss a pilot project with the aim to sensitise students to professional and moral responsibility for those who are not equally included in the ordinary system of help and to the protection gap between needs of health care and health care given.

The pilot project was conducted in the section for public health at our faculty in the bachelor programme in nursing. Within this section we use project-based clinical studies as a pedagogical tool for achieving operational competence in health promotion and preventive health care. The focus is on healthy populations as well as on groups at risk, making this section well suited to include individuals and groups facing marginalisation. Cooperation with voluntary organisations and low-threshold facilities seems to be of importance in bringing to light the various problems associated with insufficient health care for individuals and groups facing marginalisation.

The project presupposes an understanding of marginalisation. I therefore briefly discuss questions regarding marginalisation in the next section of the article.

\section{Individuals and groups suffering of marginalisation in the shadow of the Norwegian welfare state}

The human life-world is made up of family, friends, partners, work, recreation, society, history, nature and philosophy of life or religion, summed up in the concept of life contexts (Fløistad 2000; Myhrvold 2006). Because each life context has signficance in its own right and serves as a means of enriching the other, extensive losses may limit a person's possibility to participate socially and politically. We may say that each life context is corresponding to what Tranøy (1981) described as non-vital, legitimate needs in his discussion on needs and rights. 
In this discussion Tranøy made two distinctions worth attention. The first distinction is the one between legitimate and illegitimate needs. The other distinction is the one between vital and non-vital needs within the category of legitimate needs. Vital needs are irreplaceable on an individual basis and thus frustration of a vital need leads to death, severe illness or disability. This is not a controversial position. However, how to understand non-vital, legitimate needs and illegitimate needs is widely discussed. The point here is that legitimate, non-vital needs express human possibilities to fulfil an individual's potentials, to growth and to self-realisation. Although legitimate, non-vital needs are replaceable one by one; they may be irreplaceable, and thus vital, taken collectively (Tranøy 1981). Thus, to experience extensive losses may be a threat to health.

This is also in keeping with what is considered to be important underlying conditions of health from a public health point of view.

Underlying conditions of health can be summed up in general socio-economic, cultural and environmental conditions, living and working conditions, social and community networks and individual lifestyle factors (Dahlgren \& Whitehead 2007). From this it follows that underlying conditions of health have to be taken into account to a greater or lesser extent dependent on each country's economy and overall standard of health care because of the strong associations between health and these conditions. To decrease inequities in health is also a main purpose of the Ottawa Charter for Health Promotion (World Health Organisation 1986) because of its emphasis on fundamental prerequisites for health such as 'peace, shelter, education, and food' as well as on what we may associate with ethical considerations such as social justice and equity.

Dahlgren and Whitehead (2007) further emphasise that 'the most important determinants of health may differ for different socioeconomic groups', which imply 'to distinguish between social determinants of health for the overall population and the social determinants of inequities in health'. Poverty is one of their examples to illustrate this point. Poverty will account for a greater health hazard for those who are poor even in high-income countries.

Thus, underlying conditions of health seem to be corresponding to life contexts. Loss of one, as e.g. loss of work, may send a person into a downward spiral, thus inflicting new losses and limiting a person's ability to participate socially and politically. With respect to the consequences of a lack of integration in working life and other activities in society, limited opportunities for the future is a key consideration when judging whether the individual's needs are vital and legitimate. Within health care and social welfare, assessing losses therefore may be a useful way to understand marginalisation and thus who might be at risk in our society. To intervene within this wider patient context is a challenge and implies dealing with any form of marginalisation as a possible health issue.

Besides, language barriers and cultural constraints influence every person's knowledge about the community, how to apply for assistance, including the ability to make oneself understood, as well as the health professionals' ability to assess the need for health care. Understanding the significance of language goes even deeper than the issue of overcoming language barriers. According to Levinas (1998a), language presupposes interlocutors, a plurality, and implies a radical separation, the strangeness of the interlocutors in 
the revelation of the other to me. Language is spoken when a relationship is wanting and discourse is thus 'the experience of something absolutely foreign' (p. 73). In contrast, rhetoric is ruse and exploitation and 'in this sense justice coincides with the overcoming of rhetoric' (p. 72).

With a particular emphasis on challenges regarding differentness with respect to ethnicity and social status as well as breach with norms and laws, differentness in this context should be understood as 'such a high degree of distinction that it overshadows what is common and thereby becomes a threatening strangeness' (Myhrvold 2006: 126). From this, it follows that one important aspect of mature empathy involves the ability to see beyond differences and take moral responsibility for those who are different to us' (p. 131). Such an understanding of differentness may, at least partly, explain why migration may increase the risk of mental health difficulties as well as mental health disorders. Discrimination is one factor of importance to difficulties in the resettlement phase and seems to increase the risk of mental health problems and mental health disorders in particular for children and adolescents (Kumar et al. 2010).

In recent years, the street scene in Oslo has changed considerably and reflects these matters, including an increased number of beggars, migrant workers and undocumented migrants as well as an increase in open prostitution and illicit drug trading. This has stirred quite a debate and uncovered dilemmas that arise in the midst of the ongoing unresolved conflict of interest between human rights, health care and social welfare, and the security and sovereignty of the modern state. Various authorities, e.g. the police, immigration authorities and health professionals, all face these dilemmas in their daily work. Restrictive actions in Norway include the decision to criminalise the buying of sex (effective as of 1 January 2009) and the decision to revoke the temporary work permits of asylum seekers without documents (national passport) while they wait for the hearing of their asylum claims (effective as of 28 January 2009). On the other hand, those with substance abuse or substance use disorders received patient status in 2004 in Norway. In addition, the Immigration Act in Norway (effective as of 1 January 2010) states that humanitarian assistance and medical aid shall not be criminalised (Aschehoug 2010), which is important with respect to e.g. undocumented migrants' access to health care.

With respect to marginalisation, children and adolescents do not have an adult's preparedness for life, and their health and welfare are dependent on their parents and other close adults taking care of them. Children and adolescents are also vulnerable to role reversal because of the parents' substance abuse or the parents' own suffering from the effects of trauma, and the effects of trauma seem to be more severe when they occur in childhood. There is a growing body of knowledge about the associations between children and adolescents' mental illness and mental difficulties and trauma, e.g. separating from parents and being a witness to a parent's death as well as the effect of trauma on parenting (Nielsen et al. 2008; Kolodziej et al. 2005; Lustig et al. 2004; Heptinstall et al. 2004; Steel et al. 2004; Davidson et al. 2004; Mares \& Jureidini 2004; Fazel \& Stein 2003; Fazel \& Stein 2002).

In addition, health promotion and preventive health care for children and adolescents have the potential for greater gain, whether this be in the area of prevention of infectious 
diseases, the health consequences of a typical Western lifestyle or psychosocial problems. A final aspect is that in many contexts the children's particular needs become a kind of added worry in the adults' situation. Children and adolescents deserve a certain amount of attention.

Altogether, marginalisation may be understood as a multidimensional and dynamic phenomenon reflecting a complex interplay between every person's vulnerability and political, economic, social and cultural features. In brief individuals and groups facing marginalisation in Western societies reflect injustice at the global level because of war, hunger, poverty and the illegal international economies connected with the trade of drugs, weapons and people (human trafficking). The consequences of global injustice make their mark throughout the Western world.

All these cases led to my decision to identify children and adolescent minorities, refugees and people living in prostitution and/or with substance abuse or substance use disorders as groups that might suffer from marginalisation in the shadow of the Norwegian welfare state and would therefore be of particular relevance to our educational programme in fulfilling our curriculum obligations. However, individuals and groups facing marginalisation are often taken care of outside of the established health services, and thus we were in need of new cooperation partners in our efforts to contribute to informed and caring nurses as part of an educational, professional, ethical and political responsibility often called for in the area of marginalisation.

\section{Educational reorientation}

What knowledge is and what type of knowledge is required for the education of nurses and other health professionals entail, among other things, a questioning of the relationship between theoretical and practical approaches to knowledge. The balance between theory and practice deserves a discussion that cannot be addressed in full here. In my opinion, neither practical nor theoretical reasons for knowledge should be focused on unilaterally. The point of departure for this particular pilot project, however, was a realisation that practice fields are characterised by complexity, uncertainty, uniqueness and value conflicts, as described by Schön, (1983: 39) and thus have a certain value in developing knowledge. Though practice is not and should not be characterised by specific, isolated problems, a one-sided practical approach is not valid either as far as developing knowledge that works is concerned. Focusing on practice is not an alternative to or a replacement for theoretical reason, and thus professional socialisation should take place in an atmosphere of critical reflection. The student should not automatically adopt the practice field's collective notions of e.g. how they prioritise the use of resources or attitudes towards various patient groups. 


\section{Learning through participation}

As participation is decisive for achieving a feeling of belonging to a society and for meaning and identity, participation is also decisive in learning in the broad sense of the concept (Wenger 1998). We know who we are, and our own personal development is influenced by those practices we engage in as well as in those in which we do not. The extent of participation is important to our position and to '...how we engage and direct our energies, what we care about and what we neglect, what we attempt to know and understand and what we choose to ignore, .... and with whom we seek connections and whom we avoid' (Wenger 1998: 167-168).

As we have seen, this is important with respect to integration. It is also important with respect to the students' learning process as well as to mature empathy. The sources of personal growth lie inherent in the dialogue between one's own meanings, norms and ways of knowing and those of the others. Students, however, may struggle between 'fitting in' and being themselves due to their somewhat precarious status in the practice fields. 'Fitting in' is a pragmatic solution and may be easier even when the practice field's collective notions represent a breach of one's own ideals.

However, an expansion of the nursing field may push the boundaries of the nursing discipline when assessing which groups we can or should concern ourselves with and must therefore also include the organisation's development, including institutional adaptation, in order to create opportunities to investigate new practice places and new perspectives. They are intertwined.

\section{What can be done within nursing education to sensitise students to the importance of a greater attention to individuals and groups facing marginalisation?}

An analysis of our education with respect to the possible discrepancy between our requirements and what we in fact were doing with regard to our professional and moral responsibility for individuals and groups facing marginalisation proved that the teaching offered was inadequate to fulfil our obligations. A dialogical approach to knowledge was chosen to create room for interaction between the students, and individuals and groups who might be in a position of breach with the normative majority. It was the response along the way that, in dialogue with knowledge of the field, determines the path ahead. A dialogical approach to knowledge, however, is not clearly defined. In this context, such an approach is understood as requiring dialectical moves between theory and experiences/practice to develop knowledge and is here supported by a plurality of interpretation. This approach also implied a more participatory role for me than that of an external spectator, i.e. the role of a broker. Brokering may be defined as introducing elements of one practice into another, and according to Wenger, to be a broker is to 'make new connections across communities of practice, enable coordination, and ... open new possibilities for meaning' (p. 109).

To ensure dialectical moves between theory and experiences/practice, the actions taken were a simultaneous exploration and implementation of new clinical study sites for 
the nursing students in addition to typical sites as are obstetric and natal units at hospitals, expanding the courses in the ethics of care and broadening the perspectives within the courses. Within the project-based clinical studies in health promotion and preventive health care at our faculty, the students, in groups of eight to ten, design a project based on the research process and project methodology. We emphasise the students' ability to cooperate with one another, with those working at their clinical study sites, and, if possible, with the users depending on their age as well as the object of their project. Each group has to document their work in a final project report of 10000 words and present the work at their clinical study sites and at our faculty. The project period lasts eight weeks. The students cannot choose where to conduct their clinical studies. The students who participated in the exploratory phase in this pilot project had no choice either.

It is therefore important to note that the students were informed in writing about the aims of the pilot project, my own participant role, as well as eventually changes in the clinical study sites and/or in the courses due to what they articulated in their impressions. One student made a reservation. This student's responses are excluded in the following.

Exploring and implementing new clinical study sites for the nursing students started as a cooperative project with the refugee coordinator in a voluntary organisation with an emphasis on children's and adolescents' health in the refugee centres. I also had the opportunity to cooperate with other voluntary organisations and low-threshold facilities. However, in Oslo, as in other cities, some of the most vulnerable individuals may find themselves on the streets. For this reason, I took the initiative to launch the 'Nursing on the Streets' projects.

In the exploratory phase of the project, 11 groups with a total of 89 students carried out their project-based clinical studies in health promotion and preventive health care in institutions under the direction of the voluntary organisations' refugee centres (two groups), activity centres for adolescents between 15 and 25 years of age (four groups) and on the streets of Oslo (five groups). The topic, target group and the like were decided in conjunction with the users (e.g. the adolescents at the activity centres), the leaders of the centres and myself.

In 'Nursing on the Streets', however, the students did not cooperate with one specific organisation or institution. These projects involved initial observations made on the streets in Oslo with a specific emphasis on drugs, prostitution, violence or homelessness. Then a specific project question was elucidated through the use of questionnaires or interviews with a number of professionals in various institutions who work in low-threshold facilities with people on the streets and who may have a different approach to health promotion and preventive health care from that of health professionals, as e.g. social or child welfare institutions or the police.

I followed all of these groups closely, which implied approximately 500 hours of participant observation together with the students in the exploratory phase of this project. This came in addition to the weekly meetings we normally conduct with the students. 


\section{Expanding the perspectives within ethics of care}

The simultaneous efforts to expand the courses on the ethics of care and to broaden the perspectives within the courses changed the objects of the courses from a unilateral focus on the ethics of closeness to emphasise the ethical dilemmas that arise in the interface between closeness and distance, caring and marginalisation, rights and needs and priorities at different levels. The more specific aims of the course are to contribute to the students' ability to identify marginalised groups and groups at risk within the health care system, in society and on a global level, with the core concepts being empathy, justice and marginalisation, as well as phenomena the students do not necessarily experience in their clinical study sites as e.g. the impact of undocumentedness on access to health care.

All students in the second year of the bachelor programme in nursing, approximately 1400 students in the exploratory phase of this project, participated in the course on the ethics of care. As part of the course, students had to complete an assignment on professional and moral responsibility vis-à-vis individuals and groups facing marginalisation.

My own participation and a systematic, ongoing evaluation were important for qualifying the learning outcome in this continuous and participative learning process.

\section{Ongoing evaluation}

Qualitative evaluation of the lectures immediately after these were held in which a group of the students were asked to write a brief, continuous text on marginalisation, empathy, justice and so on, and similar evaluations by the students who participated in the new practice fields, input from users, employees and volunteers in the various practice groups were incorporated into the next course on the ethics of care as well as the next group's project-based clinical study. Theoretical perspectives were changed as practical experience was gathered, and these in turn were brought back to the field of practice and so on. The evaluation was not merely an evaluation of the students' satisfaction with either the course or the practice but an evaluation of how they understood the phenomena and what they thought could be done to make nurses play a part in the area of marginalisation. A retrospective reading of the students' project reports was also important to my understanding, as were my own field notes.

\section{Facing marginalisation}

This broad-based approach provided insight into some common phenomena important for persons not equally included as well as for the students' learning process. What was considered to be especially important for persons not equally included were losses of life contexts. The students' experiences of insight concerning different groups' life conditions, and what the students articulate as their own breach with stigmatising characterisations of different groups in our society, were also found to be important to the students' learning process. Important to further development of the courses were the students' various descriptions on why they found the participation in these projects of relevance to 
them. All these factors are in accordance with the students' later evaluations and are discussed here.

\section{The students' experience of relevance}

At the beginning of the project, some of the students argued that the refugees' health and welfare, minority group adolescents' acculturation struggle and big city problems such as prostitution and substance abuse were of limited relevance to nursing students. Refugees and people with a long history of substance abuse or living in prostitution were seen as being in need of social care or criminal care, not health care. These objections were not expressed by the entire group, but they did raise questions concerning the nurses' professional and moral responsibility and various aspects of the economic, social and cultural conditions for health. My answer to these objections was to spend even more time presenting the specific health problems of the particular group that the students would meet at their clinical study site in my first meeting with them.

According to the students' reactions as well as their various descriptions on why they found the participation of relevance to them in the consecutive evaluation at the end of the period, three perspectives seemed to be particular importance to the students' experience of professional and moral significance. These were perspectives on one's own life, perspectives on the society in which we all live and perspectives on nurses' professional and moral responsibility. The students' statements such as 'Now I have a better understanding of what a lucky life situation I am in myself' and 'I am so happy for the life I am living' capture the essence of (new) perspectives on one's own life.

To establish professional relationships to different groups on the margin of society also represented a breach with how the students previously had related themselves to different groups and places in the town, as this quote illustrates:

I have never been here ('Plata', downtown Oslo were many of the heavy drug addicts spend their time, my remark). My mother does not let me - it is good being together with you - I feel more secure then. I think this is absolutely terrible, but important. We do not necessarily need to know anything about this, it is important that we who are, who shall be nurses, know something about how somebody are living in our society.

Though knowledge about e.g. a possible discrepancy between the need for care and the care given for individuals and groups that for some reason are not equally included in the established health care services is not necessarily followed by a change of attitude, knowledge was important to the students' experience of the relevance of the project itself. Knowledge about health care needs also seemed to be followed by an acceptance of the importance of ethics of care, in particular that of nurses' socio-political responsibility. These experiences really seemed to open new possibilities for meaning (Wenger 1998).

Altogether the evaluation as well as what the students articulated in their impressions during the project period showed that they just had no idea, either of the very existence of different groups' need of health care due to their life situation or of the work of different voluntary organisations or low-threshold facilities. The experiences also allowed the stu- 
dents to question the role of a professional nurse, which is often defined through practical tasks, especially procedures. The following excerpt from one of the students' project reports may serve as an illustration to this:

Nursing students in project work on a refugee centre? Many people might ask if this has anything to do with nursing. Do nurses have any business there? All of us in our study group also had our misgivings. Our future role in white uniforms with medication trays, syringes and patients in beds no doubt seemed very far from the assignment we had been given. Even though many people, in our opinion, disagree about what nursing in our time should be, we have approached the assignment with an open mind. Our conviction has been that nursing is such a broad concept that it should encompass all groups of people, especially the weakest and marginalised groups in society.

Beginning with the fourth group of students, there were no more objections to the idea of nurses having professional and moral responsibility for individuals and groups facing marginalisation. Most important within perspectives on nurses' professional and moral responsibility, however, was what the students considered as major losses of different groups and their own breach with stigmatising characterisations of different groups in our society. These aspects are discussed in detail in the next section.

\section{Losses of life contexts and limited opportunities for the future}

The experiences from field observations at refugee centres and from observations on the streets of Oslo can be described as 'entering a different world from the one we knew', as one of the students articulated in her first impression of a refugee centre. Both the students and I got the feeling of visiting a parallel universe. The students' statements such as 'they don't have anything' and 'they are excluded from society' capture the essence of our reactions both at the refugee centres and on the streets.

People who engage in prostitution and those with serious substance abuse problems experience major loss, both on their journey from the norm-giving society to a life on the edge of society and on their journey from the person they once were. 'Prostitutes present themselves as people they really aren't', wrote the students in a project report on prostitutes' health as part of 'Nursing on the Streets'. Life as a prostitute and/or substance abuser leads to a life separate from others they used to be close to, and many do not take part in large and small family events. Additionally, their efforts to free themselves of drug addiction or prostitution inflict new losses.

With respect to the consequences of a lack of integration in working life and other activities in society, limited opportunities for the future are a key consideration when judging whether the individual's needs are vital and/or legitimate and are associated with extensive losses as well. Thus, institutions that establish a framework for participation and implement measures to compensate for loss can help to improve people's opportunities for the future. Assistance with homework, preparing job applications, Norwegian language instruction and the like which volunteers provide at the refugee centres and which are core activities at the activity centres are vital. Experiences from the activity centres were valuable for understanding the importance of a primary preventive measure, especially 
for minority youth, that entails regular activities in safe surroundings with others who confirm and accept them. Here the young people learned about the value of an education while receiving practical assistance to pursue an education. Circumstances reflecting the underlying socio-political conditions of health became visible to the students during the project period.

The centres also give structure and meaning to their daily lives and keep them off the streets, which is an overall aim here. The risk of recruitment to crime is among other things due to the financial temptations which can be overwhelming for young refugees, as this quote illustrates:

It is very difficult for them at home to understand that I am not rich and that I cannot send a lot of money home ......Getting an education is expensive because then you cannot send money home. In a way it is this that makes you unsuccessful. Life was easier in a way when I lived in the refugee camp in Africa.

In my effort to conceptualise our experiences, losses of life contexts (Fløistad 2000; Myhrvold 2006) were found to be parallel to the various dimensions of marginalisation. Those who are suffering from extensive losses may experience marginalisation in many of the dimensions of the phenomenon in addition to their health problems, and/or they may believe that these losses are having an impact on their health status. Participation allowed for experiences making losses of life contexts important to the students' understanding of marginalisation and thus a phenomenon that should be paid a greater attention within nursing care.

\section{Breaking down prejudices}

In my ongoing discussions with the students during their clinical studies, terms such as differentness, stigmatisation and prejudice, as well as meeting the other as an individual, as a person, were those used most often by the students to describe their experiences. Even though the focus of the students' investigations at the activity centres concerned quite ordinary topics within health promotion and preventive health care in the Western world, such as e.g. adolescence and safe sex, the large number of immigrants/minorities led to experiences similar to those at the refugee centres. The following situation described in response to the evaluation can serve as an example of this:

I felt that I was prejudiced at the start of the project. It is easy to view the group as homogeneous (Somali boys/men between 15 and 25 years, author's comment). Contact and dialogue (chess, soccer, billiards and help with homework) has made me aware of their unique personalities and positive aspects.

The eventual change in the students' attitudes towards those they came in contact with during their clinical studies was also evident in statements such as: 'I have learned a great deal and become less prejudiced. Not to put individuals into one specific category, but to meet every person as an individual'; 'I think we overcame fear of and scepticism towards a very different group (people living in prostitution) during our clinical studies. The opp- 
ortunity to encounter this group of people as individuals seems to be an important factor in the students' learning and eventual change of attitude. The students participation in the project was therefore crucial for their learning and contributes to their experience of becoming aware of their own prejudices.

The evaluation of the ethics course also pointed to the importance of challenging our tendency to transfer conclusions drawn from the group level to the individual level as well as our tendency to empathise with those we perceive to be like us (Myhrvold 2006). Studying professional and ethical responsibility for individuals and groups facing marginalisation and dilemmas that arise in the interface between e.g. closeness and distance, rights and needs at school in the course on the ethics of care may therefore enhance the students' ability to look beyond ethnic and social differences and see the underlying suffering and vulnerability with equal importance: their strength, ambitions and hopes. Mature empathy extends beyond the immediate group characterisation of the other. The challenge is to be aware of the various dimensions of marginalisation and at the same time to meet the other as a person despite any group characterisation.

Today, cross-cultural competence is required and is also achieving growing attention in nursing education. I believe, however, that cross-cultural care is somewhat limitedly understood as it is often tied more to the interaction between different minority groups from non-Western countries and the normative majority, than to the broad range of challenges also including what is at stake in different subcultures. Challenges regarding differentness should not be tied to ethnicity alone but include possible conceivable sub-cultural characters of anybody who might suffer of marginalisation in the society, to why they become outsiders. Sub-cultural characters may, however, not be distinct but hidden to the normative majority. This is important with respect to transforming knowledge from one context to another. There is quite a long distance from the classroom to downtown Oslo, or any other big city.

Broadening an understanding of cross-cultural care thus may help us to understand the very dynamic logic of marginalisation through a constant awareness of who might be at risk in our society, which is a claim within public health. Who that might be will change in a changing society, which is, as we have seen, a main point given by the ICN in their suggestions for use of the Code of Ethics for Nurses (ICN 2006).

However, this should not be understood as if ethical guidelines is all there is to ethics of care. Relevant ethical circumstances should not be left to guidelines alone. This is a point made by Sen (2010) on the discussion of human rights as legislation and human rights as ethics. Sen states that on the one side an institutionalisation of human rights makes recognising them a first step to realising them. On the other, however, a legislation of rights does not mean they will not be frustrated. To make a distinction between human rights as legislation and human rights as ethics might therefore be useful because the latter thus can be made more effective because it allows for 'a variety of interrelated instruments and a versatility of ways and means' (p. 366). We may even risk a secret approval of what is left outside (the law, the conventions and the rules) if we make the claims too detailed. As the Code says, a respect for human rights lays inherent in nursing (ICN 2006). The Code's further statements of what nursing should be unrestricted by as 'con- 
siderations of age, colour, creed, culture, disability or illness, gender, sexual orientation, nationality, politics, race or social status' thus may come to exclude those not mentioned.

To me it seemed that the students' participation allowed for diversity and differences to introduce something (else), which does more than confirm what we already know or understand, with Levinas (1998a) in the revelation of the other to me. It seemed to be important to the students' moral development as well in that participation was important to what was actually cared about. However, it presumes that we listen, that we use language to share, so that we do not remain in our own self-understanding and thus contribute to the dissemination of knowledge.

Our experiences also increased our awareness of our commonalities as human beings, seeing ourselves in others despite our differences (Myhrvold 2006). A presentation of the project reports at school provides a good illustration of this. A group of students who worked with the health of prostitutes hung a large mirror at their booth. The first thing the public saw was a mirror image of themselves, and then the questions: Who are you? Who is the other? What hopes and expectations for life do we share?

This is an important reminder, not least because participation in activities at voluntary organisations or low-threshold facilities may come to directing our attention towards differentness in itself, due to the fact that such facilities are justified through one single attribute of the group concerned as e.g. being a minority. Such experiences may thus lead more to stigmatising limitations than to our commonalities as human beings. We should not lose our common need of belonging, safety and a certain amount of predictability in life at sight. For that reason the division of labour between the governmental and nongovernmental organisations seems to be somewhat arbitrary and in need of a more conscious consideration from both parts.

\section{Concluding remarks and further work required}

The reciprocal exchange of ideas between my own participants and co-creating roles and those I cooperated with, as well as openness in relation to what is at stake in the encounter with e.g. refugees and minority group adolescents, employees in various organisations and the students have been underlying principles in this work. Providing room for the other participants to be integrally involved has been crucial as well. The simultaneous development of theory and practice in our education resulted in a mutual enrichment that was significance for the students as well as for my own learning related to the professional and moral responsibility for individuals and groups facing marginalisation.

The efforts to expand the nursing field seem to challenge the boundaries of the nursing discipline when assessing which groups we can or should include. However, the pilot project became a door opener to different clinical study sites of learning for our students. The institutional adaptation is ensured through an ongoing exploring and establishing of new clinical arenas of learning. Every year, $10-15 \%$ of the students now have projectbased clinical studies in institutions that we have not previously cooperated with as e.g. a gay and lesbian health centre, a centre for prostitutes' health, a police station and a prison. 
All students in the second year of their bachelor programme in nursing (approximately 360 every year) take a course in the ethics of care, including a task that emphasises professional and moral responsibility for individuals and groups facing marginalisation.

Evaluation data indicated that a dialogical approach to knowledge seems to benefit the students' learning. The division of labour between theory and practice deserves the constant discussion ongoing within nursing education. On one side we may say, as does de Chesnay, that 'Writing papers is useful but can be an empty intellectual exercise if not combined with developing competence in talking with people' (de Chesnay 2007: 455). On the other side there is today a reason to ask if practice, which constitutes $50 \%$ of the education of nurses in Norway, is too highly prioritised. Anyhow, it seems to be an unhappy split between theory and practice and a need to strengthen our efforts to build bridges between them. Theory and practice should not be viewed as antagonists.

The students who have participated in the exploratory phase of the project have been dedicated and idealistic in their efforts to learn what to our education were new practices and new perspectives on health care and ethics of care. Evaluation data indicated that cooperation with voluntary organisations and low-threshold facilities with a long tradition of trying to prevent people from 'falling through the net' seem to be bringing to light the various problems associated with insufficient health care for individuals and groups facing marginalisation. Thus, such cooperation seems to be a relevant approach for a nursing education programme that includes individuals and groups facing marginalisation.

The participation in projects like these also seems to give valuable experiences of importance to the next generation of nurses' awareness of the need for social action concerning individuals and groups facing marginalisation and may help them to play a role in setting priorities both at a political and institutional level to the benefit of the least advantaged in our society. However, we cannot be sure of whether experiences like these will contribute to the development of the students' mature empathy when meeting individuals who face marginalisation as patients in a different context. A potential follow-up study of a group of students over time, throughout their education and afterwards as professional nurses, might give an important contribution regarding this matter. Preferably, such a follow-up should be conducted in a working environment where the (marginalised) group itself is not the target group but nevertheless is represented (e.g. at hospitals).

However, I would like to emphasise the students' eye-opening experiences during the practice period and that the complex evaluation indicated that participation that allowed for moments of meeting seemed to be an important factor to the students' awareness of their own prejudices and thus the revelation of differentness' as one important factor to be aware of within ethics of care. Losses of life contexts as well as associations between health and underlying conditions of health also serve as valuable approaches in the discussion on dilemmas that arise in the interface between closeness and distance, rights and needs and any dimension of marginalisation as a possible health issue. These phenomena, however, are in need of further conceptualisation and discussion not least because different groups not only are excluded accidentally but are even excluded intentionally as is the case for undocumented migrants. 
The representation of individuals and groups facing marginalisation does have politi$\mathrm{cal}$, practical and ethical implications. Questioning how to organise our health services to include those who are in need of help in spite of any precarious status is a challenge to health professionals more as 'groups' than as individuals. There is after all a limit to how much of any one's suffering we are able to act upon as individuals. As health professionals, however, there is a need to take a common responsibility against any barriers to access health care. This is important not least because the institutional arrangements affect every health professional's chance of fulfilling their professional and moral commitment when meeting individuals facing marginalisation in need of health care.

As long as the ordinary system for help does not assure everyone adequate health care, nursing education programmes have a common challenge to highlight marginalisation as a possible health issue in general, and in the ethics of care in particular, in our efforts to make us play a part as informed and caring nurses as part of an educational responsibility often called for in the area of marginalisation.

\section{Acknowledgements}

I would like to thank the students in the bachelor programme at the Faculty of Nursing, Oslo University College (from August 1st 2011, Oslo and Akershus University College of Applied Sciences), for their enthusiastic participation in this project and for their valuable critical feedback. I would also like to thank the University College for making it possible to do this work. I am grateful to the institutions that warmly welcomed both the students and me, and I extend a special thanks to Vidar Remfeldt and Hilde Marie Rhoden.

\section{Literature}

Aschehoug, S. (2010) Rett til helsehjelp for papirløse migranter (The Right to Health for Undocumented Migrants). Tidsskrift for den norske Legeforening (The Journal of the Norwegian Medical Association), 130, pp. 765-766.

de Chesnay, M. (2007) Teaching Nurses about Vulnerable Populations. In Caring for the Vulnerable Perspectives in Nursing Theory, Practice, and Research, eds. M. de Chesnay \& B.A. Anderson, pp. 453-460. Ontario, Canada: Jones and Bartlett Publishers.

Dahlgren, G. \& Whitehead, M. (2007) European strategies for tackling social inequities in health: Levelling up part 2. Copenhagen \& University of Liverpool: World Health Organisation.

Davidson, N., Skull, S., Burgner, D., Kelly, P., Raman, S., Silove, D., Steel, Z., Vora, R. \& Smith, M. (2004) An issue of access: Delivering equitable health care for newly arrived refugee children in Australia. Journal of Paediatric Health, 40, pp. 569-575.

Fazel, M. \& Stein, A. (2003) Mental health of refugee children: comparative study. British Medical Journal, 327, p. 134.

Fazel, M. \& Stein, A. (2002) The mental health of refugee children. Archives Of Disease In Childhood, 87 (5), pp. 366-370.

Fløistad, G. (2000) Utfordringer: Studier i langsomhetens filosofi (Challenges: Studies in the Philosophy of Slowness). University of Oslo, Norway. 
Heptinstall, E., Sethna, V. \& Taylor, E. (2004) PTSD and depression in refugee children. Associations with pre-migration and post-migration stress. European Child \& Adolescent Psychiatry, 13 (6), pp. 373-380.

International Council of Nurses (2006) The ICN Code of Ethics for Nurses. Retrieved 9 January 2010 from http://www.icn.ch/images/stories/documents/about/icncode_english.pdf

Kolodziej, M.E., Griffin, M.L., Najavits, L.M., Otto, M.W., Greenfield, S.F. \& Weiss, R.D. (2005) Anxiety disorders among patients with co-occurring bipolar and substance use disorders. Drug and Alcohol Dependence, 80, pp. 251-257.

Kumar, B., Oppedal, B., Blystad, H., Dalgard O.S. \& Vangen, S. (2010) Helse blant flyktninger og innvandrere (Refugees and migrants' health). In Folkehelserapport 2010: Helsetilstanden $i$ Norge (The Status of Public Health in Norway 2010), eds. E.-K. Grøholt, L. Grøtvedt, H. Hånes \& G. Stene-Larsen, pp. 55-58. Oslo: Nasjonalt folkehelseinstitutt (The Norwegian Institute of Public Health).

Levinas, E. (1998a) Totality and Infinity. Pittsburgh, PA: Duquesne University Press.

Lustig, S.T., Kia-Keating, M., Knight, W.G., Geltman, P., Ellis, H., Kinzie, J.D., Keane, T. \& Saxe, G.N. (2004) Review of Child and Adolescent Refugee Mental Health. Journal of the American Academy of Child and Adolescent Psychiatry, 43 (1), pp. 24-36.

Mares, S. \& Jureidini, J. (2004) Psychiatric assessment of children and families in immigration detention - clinical, administrative and ethical issues. Australian and New Zealand Journal of Public Health, 28 (6), pp. 520-526.

Myhrvold, T. (2006) The different other - towards an including ethics of care. Nursing Philosophy, 7, pp. 125-136.

National Curriculum Regulations for Nursing Programmes (2004) Ministry of Education and Research, Norway.

National Curriculum Regulations for Nursing Programmes (2008) Ministry of Education and Research, Norway.

Nielsen, S.S., Norredam, M., Christiansen, K.L., Obel, C., Hilden, J. \& Krasnik, A. (2008) Mental health among children seeking asylum in Denmark - the effect of length of stay and number of relocations: a cross-sectional study. Public Health, 8, pp. 293-301.

Schön, D.A. (1983) The reflective practitioner: How professionals things in action. New York: Basic Books.

Sen, A. (2010) The Idea of Justice. London: Penguin Books.

Steel, Z., Momartin, S., Bateman, A.H., Hafshejani, A. \& Silove, D.M. (2004) Psychiatric status of asylum seeker families held for a protracted period in a remote detention centre in Australia. Australian and New Zealand Journal of Public Health, 28 (6), pp. 527-536.

The Ethical Guidelines for Nurses (Yrkesetiske retningslinjer for sykepleiere) (2011) Oslo: The Norwegian Nurses' Organisation (Norsk Sykepleierforbund).

Tranøy, K.E. (1981) Needs, Rights and Justice. Paper at the Tenth Interamerican Congress of Philosophy, Tallahassee, Florida, 18-23 October.

Wenger, E. (1998) Communities of Practice Learning, Meaning, and Identity. Cambridge: Cambridge University Press. 